\title{
Spatial and Social Boundaries in Gentrified Neighbourhoods
}

\author{
ZDRÁHALOVÁ Jana ${ }^{1, \text { a * }}$ \\ ${ }^{1}$ Thákurova 9, Prague - Dejvice, 166 34, Czech Republic \\ a zdrahjan@fa.cvut.cz
}

Keywords: Boundary, interface, threshold, primary boundary, secondary boundary, space syntax.

\begin{abstract}
In the paper we analyse the character of spatial boundaries of buildings and examine their correlation with social changes. For a case study we use Holesovice, a quarter of Prague, Czech Republic. This city part is a typical example of originally industrial suburb with a large number of factories, docks and railway station, all built mainly in 19. century. In the last 15 years the area has gone through gentrification that significantly changed its urban and architectural face. The transformation also affected the character of services and cultural facilities available in the area.

We compare boundaries of the original construction and boundaries of the new developments built in the last 15 years. The analysis is done at the scale of buildings. Our methodological framework is based on the Space Syntax theory and Urban Morphology. The studied characteristics are integration of accessible spaces and design of boundaries. The paper identifies urban and architectural features that correspond and reflect the lifestyle of the gentrified part of population.
\end{abstract}

\section{Introduction}

In this paper we present the results of research aiming at the analysis of spatial forms produced by new development built during the last 15 years. As a case study we use Holesovice, a former industrial suburb, currently inner part of Prague. We compare the new development with the original buildings and show that the new construction uses different urban typology. Our focus is on two attributes that distinguish the new typology from the original one. The first attribute is the character of boundaries between buildings and public space, the second one is the spatial composition of the objects. Boundaries in a city can be analysed at different urban scales. As we are interested in the people's perception, we focus on boundaries at the house - street level.

We use Space Syntax methodology [4] and the established representational methods of Urban Morphology [7] to describe the changes. Our aim is not only to describe the spatial characteristics of new developments but also to show how new spatial relationships and architectural expression correlate with social solidarity of inhabitants. In general, people develop two types of social solidarity: spatial and transspatial [2]. Spatial solidarity is characterised by strong relations with physically close people and institutions, e.g. neighbours, local shops, schools, employers. On the other hand, transspatial solidarity relies on shared interests regardless of the distance. Examples include religion, possibility to engage in distant social, cultural or educational activities, working at distance, activities using social networks (Facebook, Twitter).

Space syntax understands city as a relational system with complex organization of socio-spatial units. The analysis focuses not only on the relationship between individual city components but also investigates the relationship of parts to the whole. We will assess the accessible space, such as streets, squares or open spaces in terms of their integration within the city. Integration value is a measure formally defined in Space syntax theory [4]. The higher the integration value of a space, the higher chance this space will be a part of people's "natural movement" [4]. On the contrary if a place has a low integration value it becomes rather segregated and the chance that people will pass through is small. The spatial analysis is carried out using the Depthmap software [6]. It transforms the street map into the segment map, calculates the integration values and represents these values in the map by different colours. The colour range is from red, which denotes the place with the highest integration over orange, yellow, green down to blue, which represents the lowest integration. 


\section{Boundary - Threshold - Interface}

The role of a boundary is to divide the whole into parts that have different characteristics. The part that is inside is called interior, the surrounding part is called exterior [4]. In addition to the creation of the spatial division, the boundary also defines a social division - it separates two groups of people/users. We will call the users of the interior inhabitants, the users of the exterior are called strangers. Possible interactions between the two groups depend on the ability of the boundary to operate as an interface or on the existence of thresholds [5].
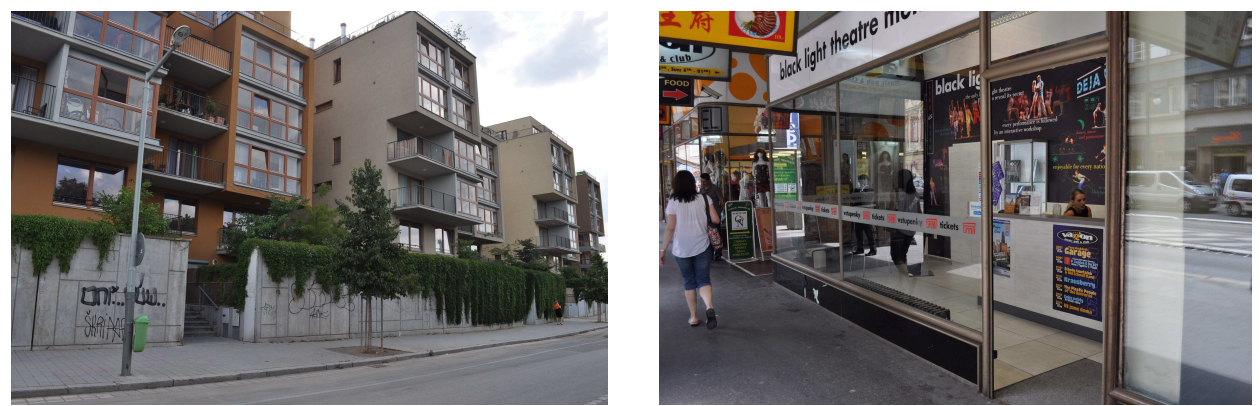

Fig. 1. Boundary - solid wall at Varhulikove street with entrances (thresholds) at Holesovice; transparent interface at Vodickova passage

Threshold is a place that facilitates transition between interior and exterior, it is an "entrance" where the boundary is penetrable, see Figure 1. A person who moves from the interior to the exterior and vice versa changes his/her status. The inhabitant turns into a stranger and vice versa.

The boundary can also have a form of interface. The interior and exterior can engage in a dialog without the need to change individual's status. Examples are glass facades of hotels, cafés and other services as expressed in Figure 1. For example a person just walking by (stranger) can see what is in the shop window or in a cafe without the need to enter the shop.

Based on the relationship to public space we may distinguish a primary and secondary boundary. Primary boundary is formed by the houses themselves, whereas in the case of a secondary boundary the house is separated from the public space by other elements such as low fencing, solid walls, greenery, etc. [1] [3].

\section{Case study Holesovice}

We will demonstrate different boundary types on the case study Holesovice, originally an industrial suburb of Prague. Until 1875 new development was impossible inside the fortified city of Prague because there was not enough space for massively expanding factories and accompanying housing. Consequently, during the second half of 19. century, many suburbs grew outside Prague. New industrial suburbs such as Karlin, Smichov, Liben or Holesovice were attached to the fortification walls, next to the river, connected with the city by railway. After the demolition of the walls the suburbs gradually joined the city of Prague. Holesovice became a quarter of Prague in 1884.

Our analysis focuses on the Eastern part of Holesovice and the transformations of this area since 2000. This part of Holesovice included the large railway station, number of food factories, such as dairy, bakery, brewery, mill, docks, slaughterhouse and many others. The urban form of Holesovice reflects its mainly industrial development. The street pattern is a regular grid with the largest urban blocks in Prague.

After WW2 the development in Prague concentrated on building mass panel housing in the peripheral areas. The inner parts of the city were left in a poor technical and moral state. The change of economic model that started in 1990 opened the state economy to global markets. As a consequence in 1990's many factories left the Czech Republic to countries with less restrictive regulations and cheaper work force. Economic transformation resulted also in social changes. The 
city lost its industrial character, blue-collar jobs lost their importance. New professions emerged in sectors such as services, media, IT, creative professions, education or banking. As a consequence the image of the city changed to post-industrial with reconstructions and renovations of old factories and new construction on abandoned plots. The new interest for living in an inner city is referred to as the "back to city movement". The new inhabitants are typically people working in the new services, with higher social status compared to the original inhabitants. Their arrival to the inner city is an expression of their free choice not a necessity. This trend can be described as a gentrification. The process of gentrification can be characterised by arrival of socially strong people, housing reconstructions, constructions of new buildings and by attracting luxurious services into the area.

Eastern Holesovice is a typical part of Prague where it is possible to observe the gentrification process. The area lost most of its factories and was left with large unused plots. With a short distance to the historical centre of Prague, closeness to the river, good transport connection to the city and its industrial image it was a great place where new exclusive development would emerge. On the site of former factories and docks projects such as The Towns Brewery, Classic 7, River Lofts, Prague Marina or Lighthouse have been realised, see Figure 2. In addition to residential and office construction, new art galleries such as DOX, theatre La Fabrica, design shops, SaSaZu restaurant or Italian Tutto Bene shop have been set up. Figure 2 shows the analysed part of Holesovice with light grey colour representing the original houses and dark grey the new developments built after 2000 .

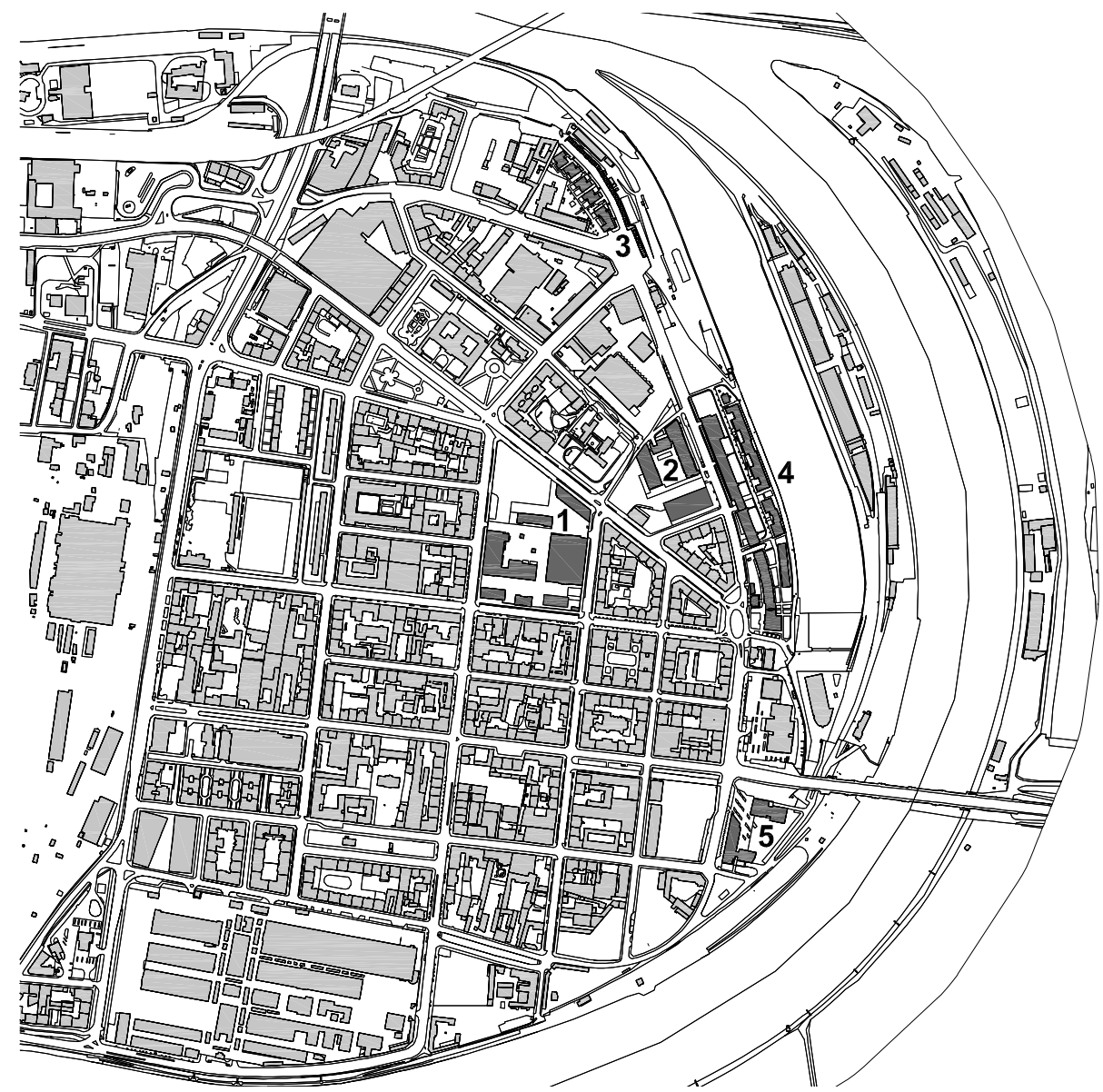

Fig. 2. Holesovice 2013, light grey represents the original construction, dark grey colour represents the new developments - The Towns Brewery (1), Classic 7 (2), River Lofts (3), Prague Marina (4), Lighthouse (5)

In Figure 3, the area is shown with streets transformed into axial lines and analysed with the Depthmap software [6]. Additional area of 2000 meters is included to eliminate the edge effect. In the regular grid, the integration value is high as indicated by red colour (in the $\mathrm{B} / \mathrm{W}$ version the 
darkest colour). In this paper we analyse two new developments: The Towns Brewery and Classic 7. These developments are well integrated at the periphery indicating that within Holesovice they are well accessible. On the other hand, the open spaces created by the clusters of houses have lower value of integration drawn as blue lines (in the $\mathrm{B} / \mathrm{W}$ version the lightest grey). There is a significant difference between the integration of the open space of the developments and the integration of the peripheries though the open spaces are visually and physically connected with the surrounding streets.

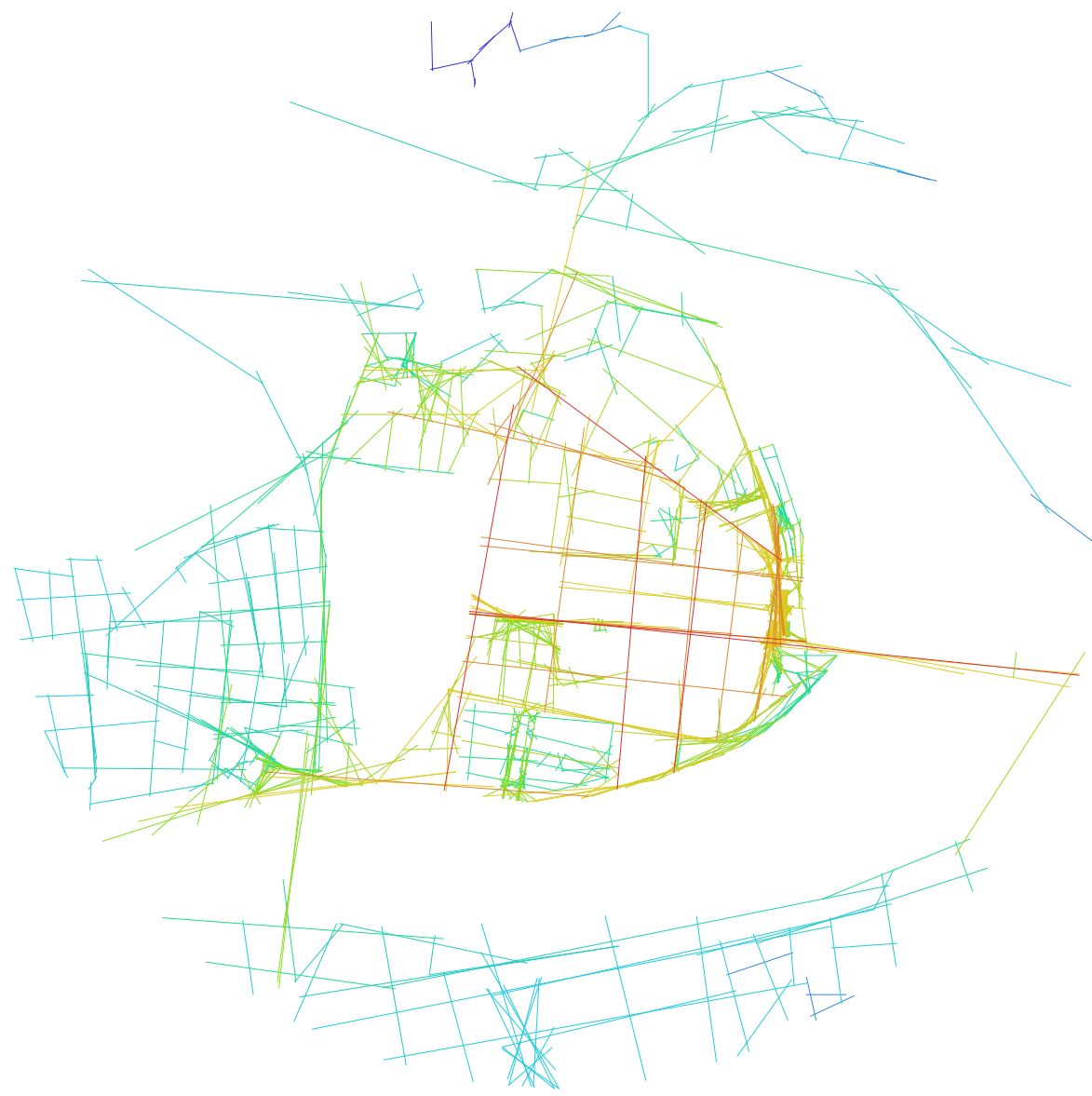

Fig. 3 Axial map of Eastern Holesovice, Segment Angular Integration of freely accessible space, $\mathrm{R}=2000$, Depthmap software [6]

The Towns Brewery. The former brewery has been converted into a multifunctional complex with residential use, offices and commerce. The development includes also newly built objects. Inside are food shop, restaurant, travel agency, life style shops and other facilities. The Towns Brewery is also the seat of Ringier Alex Springer CZ publisher.

The separation of the The Towns Brewery from surrounding streets is shown in Figure 4. In the outward direction i.e. towards the surrounding streets, a clear edge exists formed either by a solid wall or by the buildings themselves. The wall represents a boundary with occasional threshold in the form of a gateway that leads to the open space. Otherwise the wall has no openings. The separation of the new development from U Uranie street is formed by the primary boundary of the facade of the new object. Thresholds - entrances to the residential units, are the only openings facing the street at the ground level. In the direction towards the Komunardu street the building has the façade made of glass panels placed over a massive wall. It is another example of boundary-type separation. The new object at the corner of Komunardu and U Pruhonu streets has commercial function, but even though the building has semi-transparent window panels at the ground level, these do not function as shop windows and the inner part does not communicate with the outer space. Consequently, the facade plays more the role of a boundary than of an interface. 

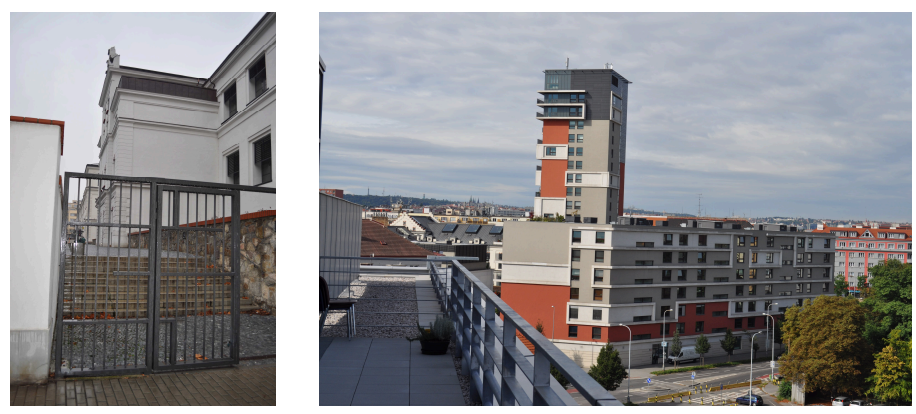

Fig. 4. The Towns Brewery, transparent gate in the surrounding wall; boundary facade at $U$ Uranie street with entrances as thresholds

The complex reminds the original private manufactory with well-defined edges towards outside, however the inner courtyard is at present accessible. You can enter it through five gateways, some of which are permanently open. All services, shops and restaurants including the food shop that serves the whole neighbourhood are accessible only from the courtyard. The new residential object accessible from $U$ Uranie street has balconies facing the courtyard. This facade is separated by secondary boundary designed as a landscape strip, see Figure 5.
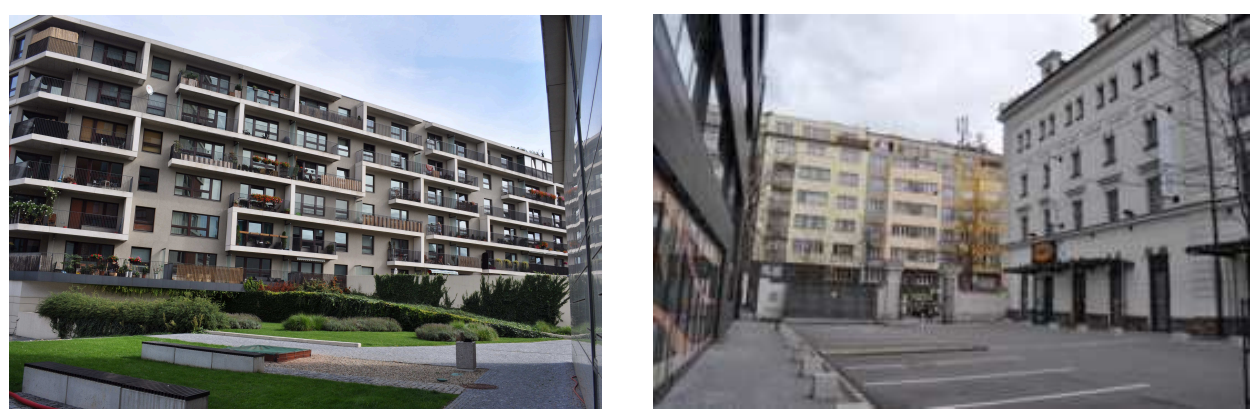

Fig. 5. The Towns Brewery, landscape strip as a secondary boundary at the inner courtyard; inner courtyard

The separation of The Towns Brewery from the surrounding streets has a unique character because the conversion of a former industrial complex had to satisfy requirements on the preservation of historic urban style. In the following section we will introduce Classic 7 as another example of development. Though it also includes objects with monument preservation constraints, it addresses the task of separation in a different way.

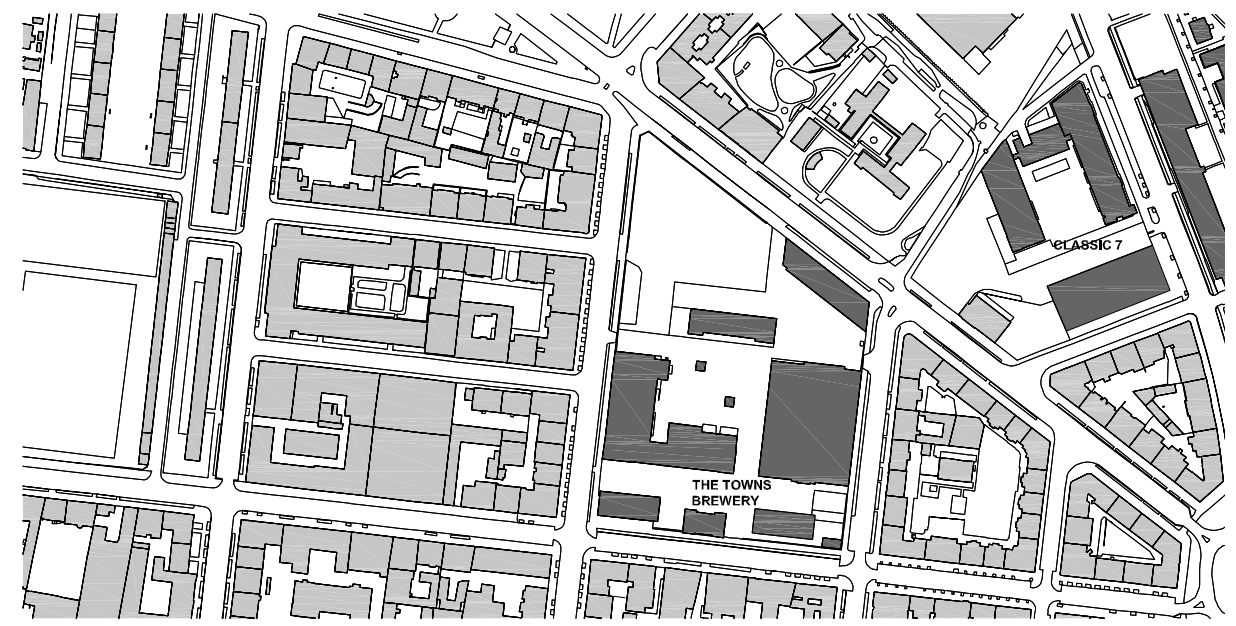

Fig. 6. Holesovice, light grey - original construction, dark grey - new developments The Towns Brewery and Classic 7 


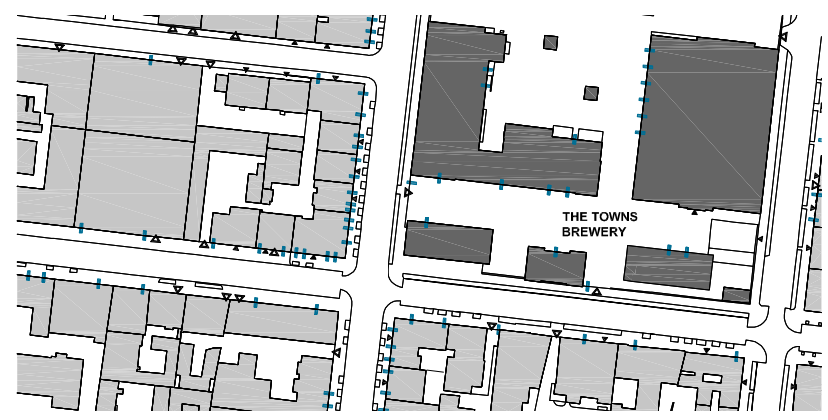

Fig. 7. Holesovice, dark gray - The Towns Brewery development, light grey - original construction; (blue) rectangles - entrances to offices or commerce, black arrows - entrances to residential objects, large arrows - vehicle entrances

Classic 7. This development is a conversion of former mills into the office complex supplemented with small retail spaces. It includes a new object that connects the existing buildings of the mills and another freestanding object, see Figure 6. There are no hard edges such as walls or fencing that would separate the complex from surrounding streets.

The separation is mainly by primary boundary created by the objects themselves. Compared to the Towns Brewery there are no robust physical boundaries between the streets and the open space created by the cluster of buildings forming the complex. However, there is still a clear distinction of the complex inside and outside areas achieved by using different material, see Figure 8, and exclusive design of the open space. In addition, the entrance to the complex is clearly marked as "Private property", see Figure 8.
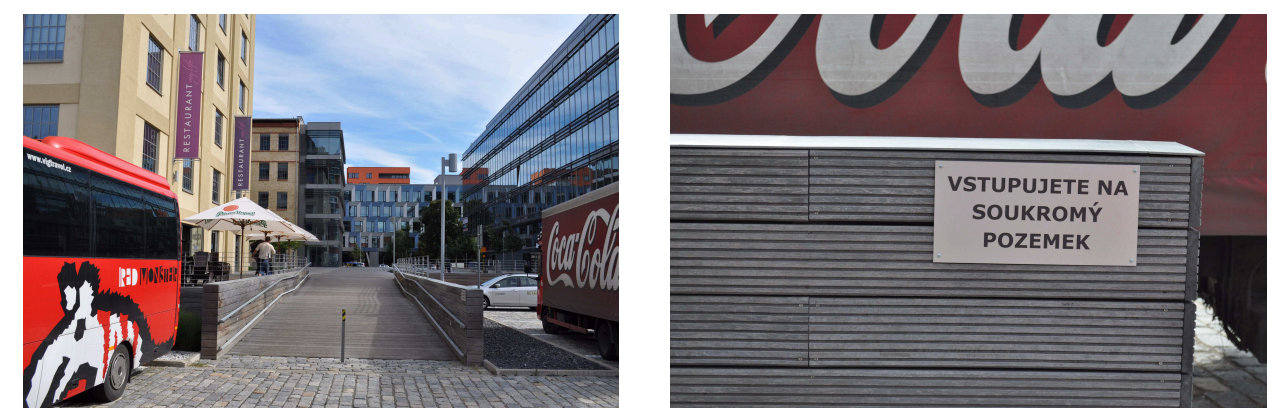

Fig. 8. Classic 7, separation of the open space by the use of different material; "Private property" sign

Typical feature distinguishing the new development from the original building construction is the number of entrances. The new development has noticeably fewer entrances than the original houses. In Figure 7, the blue rectangles represent entrances to offices and commercial facilities, and black arrows show entrances to residential units. Figure 9 shows the design of a façade of Classic 7 where the threshold in the boundary is designed as a bridge over a ditch with the rest of the facade inaccessible. Figure 9 shows the café separated from the street by a lawn strip.
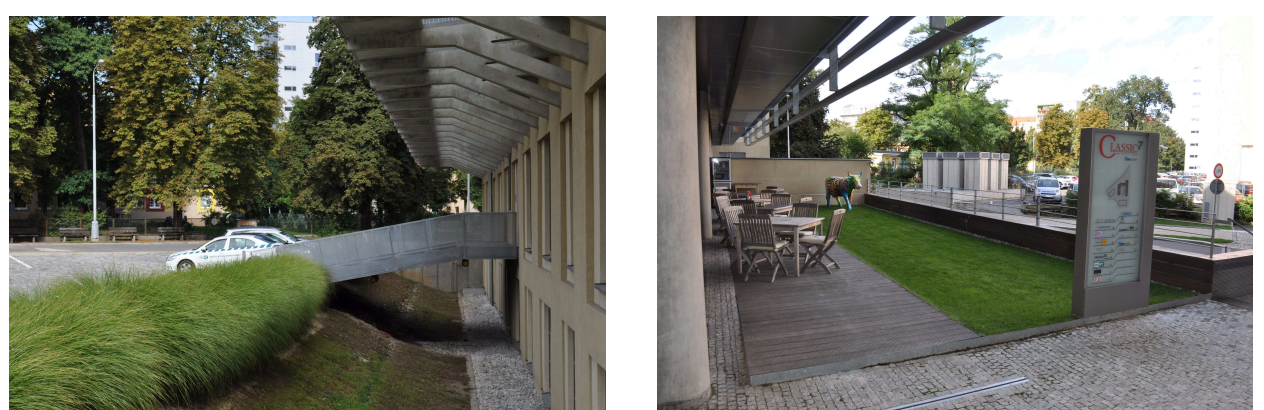

Fig. 9. Classic 7, entrance designed as a bridge over a ditch; café separated from the street by a lawn strip 


\section{Summary}

The new development, here represented by The Towns Brewery and Classic 7, differs from the original construction by the character of their boundaries and by the composition.

The original buildings are organized into urban blocks with clear separation from surrounding streets. The separation has a form of primary boundary with many usually direct entrances (thresholds) and shop windows that operate as interfaces. Inside the urban blocks are private inaccessible courtyards.

The spatial organization of the new development is designed as a cluster of objects with open space between them. It uses both primary and secondary boundaries. Even though the open space is often accessible and visually connected with the surrounding streets random visitors are deterred from entering by the very composition. This is reflected in a very low integration value calculated by the Space Syntax software.

There are other ways that discourage people from entering open spaces. For example the architecture of secondary boundaries, consisting of a transparent fencing or low gateways. Even though the gates are permanently open it psychologically discourages people from entering. Another example is the "exclusive design" of the open space using high quality materials, water or landscape features. This does not prevent people from using the open spaces, but it does not encourage natural mixing of people with diverse social solidarity.

The new development acts like a "fortresses" regardless whether it is surrounded by walls or whether the separation is achieved by the design of open spaces or the character of boundaries.

The original urban design and composition of buildings in Holesovice encourages unmediated contact of inhabitants with public space of streets and squares and therefore encourages the development of spatial solidarity. On the other hand, architectural and urban properties of the rebuilt area of Holesovice reflected in the integration value tend to support the transspatial solidarity of inhabitants. This corresponds with the expectations and life style of gentrifiers living in the new development.

Our research has shown that the Space Syntax methods and the analysis of boundaries and open space are well applicable to the new development and characterise the impact of gentrification on architecture and urban design.

\section{References}

[1] J. Hanson, Urban transformation. A History of Design Ideas. Urban Design International 5. 97122. Stockton Press, 2000.

[2] J. Hanson, B. Hillier, The Architecture of Community: Some New Proposlas on the Social Conseguences of Architectural and Planning Decisions. Arch\&Comport. /Arch. Behav and Vol $3 \mathrm{~N}$ 3. pp. 251-273, 1987.

[3] J. Hanson, R. Zako, Communities of Co-presence and Surveillance, how public open space shapes awareness and behaviour in residential developments. Proceedings, 6th International Space Syntax Symposium, Istanbul, 2007.

[4] B. Hillier, J. Hanson, The Social Logic of Space, Cambridge University Press, 1984.

[5] G. Palaiologou, L. Vaughan, Urban Rhythms: Historic Housing Evolution and Socio Spatial Boundaries. Paper ref\#8161 Proceedings: Eighth International Space Syntax Symposium Edited by M. Greene, J. Reyes and A. Castro. Santiago de Chile: PUC, 2012.

[6] A. Turner, M. Doxa, D. O'Sullivan, A. Penn, From isovists to visibility graphs: a methodology for the analysis of architectural space. Environment and Planning B: Planning and Design 28:103$121,2001$.

[7] J. W. R. Whitehand, Conzenian Urban Morphology and Urban Landscapes, 2007. 